\title{
Percepção de impacto pós-doutoral nos processos de ensino-pesquisa: desenvolvimento e validação de um questionário
}

Pedro Marcos Roma de Castro pedro.castro@capes.gov.br 0000-0002-5990-1597

Coordenação de Aperfeiçoamento de Pessoal de Nível Superior (CAPES), Brasília, Distrito Federal, Brasil.

Geciane Silveira Porto geciane@usp.br

0000-0001-6104-3627

Universidade de São Paulo,

Ribeirão Preto, São Paulo, Brasil.

\section{RESUMO}

A literatura especializada nos estágios pós-doutorais, conforme exposta em Castro e Porto (2016), é focada no impacto do pós-doutorado sobre produção científica. Não se considera nos estudos uma avaliação mais subjetiva dos docentes. Parte disso se deve à falta de instrumentos confiáveis de coleta de dados para investigação em amplitude das percepções, não apenas sobre produção bibliográfica, mas nos processos de ensinopesquisa da pós-graduação. Este trabalho relata experiência de construção de questionário nesse sentido. Os itens construídos foram testados em uma amostra de 978 professores universitários e as respostas foram submetidas a análises fatoriais com rotação oblíqua produzindo dois tipos de estruturas empíricas das quais emergiu uma escala de percepção de impacto pós-doutoral em processos de ensino-pesquisa com alto índice de confiabilidade. Com a devida validação são discutidas as aplicações desse questionário nas pesquisas sobre avaliação de programas de educação continuada e sugeridos mais estudos e aplicações nesse sentido avaliativo.
\end{abstract}

PALAVRAS-CHAVE: Psicometria. Treinamento, desenvolvimento e educação. Capacitação profissional. Medidas em avaliação. Gestão de ciência e tecnologia. Educação continuada. 


\title{
INTRODUÇÃO
}

\begin{abstract}
“O pós-doutorado, não deveria ficar a cargo do critério individual do docente, deveria entrar no planejamento dos departamentos das IES de acordo com o interesse comum da Instituição, e, de alguma forma deveria ser cobrado dos docentes o conhecimento adquirido no estágio pós-doutoral." (Docente participante da pesquisa. Área de Medicina, egresso da Capes, com pósdoutorado realizado na Espanha).
\end{abstract}

A citação ilustra de forma pontual um pensamento recorrente na academia, a que pressupõe que as atividades de capacitação docente, sejam vistas como parte de um planejamento estratégico maior e que estas atividades pressuponham algum tipo de retorno/impacto. Este trabalho relata a experiência de construção e validação de um instrumento de percepção de impacto das atividades pósdoutorais sobre os processos de ensino e pesquisa na pós-graduação brasileira; baseada na abordagem teórica/empírica proposta pelo modelo IMPACT, de autoria de Abbad-OC (1999), trata-se de pesquisa de campo desenvolvida com o intuito de identificar indicadores de impacto do estágio pós-doutoral de uma forma mais ampla, dentre esses indicadores, sobressaiu-se um fator misto entre atividades de ensino-pesquisa, com a percepção de impacto, os quais, sob a forma de um questionário, foram submetidos a procedimentos de validação semântica, conceitual e empírica.

Apesar da importância de tais medidas, nota-se conforme revisão da literatura realizada por Castro e Porto (2016), que não apenas os instrumentos e medidas são escassos nesse âmbito, mas também o próprio objeto/fenômeno investigado - estágio pós-doutoral - ainda é em extremo, um fenômeno pouco estudado. Sendo, portanto, um campo de investigação com imenso potencial de pesquisa e praticamente em aberto, o que impulsiona por sua vez, métodos e escalas de suporte para uso por parte dos pesquisadores interessados no tema e que ainda são pouco utilizadas/difundidas no Brasil.

Embora sem medida psicometricamente válida, anteriormente uma pesquisa brasileira referente à percepção de impacto da capacitação docente nas atividades de ensino, pesquisa e extensão, foi realizada por Souza (2002) e que a priori sinalizou a aplicabilidade do modelo IMPACT fora do ambiente organizacional empresarial, a indicar a possibilidade do modelo ser útil também no contexto organizacional acadêmico e sugerindo na pesquisa que sobretudo variáveis organizacionais de suporte eram fortes prognósticos de impacto.

A pesquisa de Souza (2002) na busca da investigação de impacto, não examinou a situação do pós-doutorado, mas examinou a qualificação docente (analisada por meio da titulação em nível de mestrado e doutorado) e a possível influência sobre os resultados institucionais da universidade (analisada em termos do ensino, pesquisa e extensão). O questionário elaborado por Souza (2002) foi baseado em Abbad-OC (1999) e readaptado nessa pesquisa, servindo de base para construção de um questionário perceptual moldado ao contexto da capacitação pós-doutoral e seus possíveis impactos.

Tais questões de pesquisa relativas à capacitação docente, certamente seriam mais bem avaliadas, caso houvesse um instrumento específico de suporte para investigação de impacto que possibilitasse a padronização da coleta de dados acerca do referido construto e que permitisse exame mais sistemático dos relacionamentos entre as diversas variáveis envolvidas no fenômeno. 
Outras áreas de pesquisa também careciam de medidas de suporte, principalmente as que estavam preocupadas em estudar o impacto exercido por variáveis do nível organizacional, no nível do sistema de pós-graduação e sobre o desempenho no trabalho. Isto porque segundo Castro e Porto (2016), todos os [poucos] estudos sobre o impacto pós-doutoral esqueceram-se de investigar a percepção dos docentes; ao focar apenas a produção científica e possíveis incrementos no sistema Lattes, sobremaneira, as pesquisas em transferência de treinamento pós-doutoral também necessitavam de instrumentos capazes de medir, de forma sistemática, as variáveis perceptuais e subjetivas, responsáveis pela aplicação no trabalho de conhecimentos adquiridos em estágios pósdoutorais.

Nas organizações em geral observa-se uma preocupação com a capacitação das pessoas, visando proporcionar-Ihes qualificação ou competência para o exercício das atividades laborais. A importância desse setor cresceu notadamente com a Teoria do Capital Humano, proposta por Schultz (1973), que associa os investimentos em educação à aquisição de conhecimentos e capacidades pelas pessoas e, por consequência, à superioridade produtiva de países, no nível macro e organizações, no nível micro.

Dentro dessa perspectiva, as organizações têm fomentado e desenvolvido atividades para tornar o trabalhador mais eficiente e eficaz no exercício do trabalho. Essas atividades são historicamente chamadas de Treinamento e Desenvolvimento, formando uma área específica de pesquisa e aplicação do conhecimento conhecida como T\&D, esta mesma área - já tradicional na administração, foi ampliada nos últimos anos para a nomenclatura T,D\&E Treinamento, Desenvolvimento e Educação nas organizações e trabalho (BORGESANDRADE; ABBAD; MOURÃO, 2006).

O discurso atual e recorrente acerca da necessidade de mudança organizacional, os rápidos avanços tecnológicos, a instabilidade, a globalização... fazem parte do cenário internacional e demandam mão-de-obra qualificada e polivalente. Os treinamentos e capacitações, de forma geral, agem enquanto peça importante na construção desse perfil. O campo de Treinamento, Desenvolvimento e Educação, ganha então destaque dentre outros aspectos, dado a sua relevância para o incremento no campo do conhecimento e inovação (NONAKA; TAKEUCHI, 1997), aprendizagem nas organizações (SENGE, 1999), avanços tecnológicos aliados à diversidade e mobilidade nos locais de trabalho (SCHNEIDER, 1999) e foco no conhecimento enquanto diferencial competitivo (DRUCKER, 1993).

Ao considerar-se a atividade pós-doutoral dos docentes, como um fenômeno à luz das atividades de T,D\&E no contexto da pós-graduação conforme sugerido por Castro e Porto (2016), fica claro que essas atividades não são apenas de formação/qualificação, são sim de aperfeiçoamento profissional, mas com um sentido organizacional/estratégico que busca algum tipo de retorno/impacto, pois configuram-se enquanto investimento (BOOG, 1980; SOUZA, 2002) e esforço organizacional na direção de favorecer oportunidades de aprendizagem aos seus integrantes (BASTOS, 1991, BORGES-ANDRADE, 2002, BORGES-ANDRADE; ABBAD; MOURÃO, 2006, SOUZA, 2002).

Em sentido amplo, a investigação de impacto no âmbito das atividades de TD\&E, é notadamente uma atividade de avaliação. A avaliação de programas de 
capacitação constitui um exame sistemático e rigoroso, a partir de critérios específicos, do andamento e dos êxitos obtidos por uma política ou programa e dos efeitos esperados nos grupos-alvos. A pesquisa de avaliação em TD\&E não possui um tipo particular de delineamento, pode utilizar vários métodos como survey, métodos correlacionais, experimentos ou quase-experimentos e também métodos qualitativos, como entrevistas e observação visando captar quão bem um programa opera e quais os resultados produzidos (MOURÃO; PUENTE-PALACIOS, 2006).

$\mathrm{Na}$ literatura científica são encontrados vários modelos de avaliação delineados especificamente para aferir resultados de programas instrucionais de qualificação e/ou de aperfeiçoamento, dentre eles pode-se destacar o modelo de Kirkpatrick (1976), o modelo de Hamblin (1978), o modelo investigativo de Lorenz (1980), o modelo de Avaliação Integrado e Somativo (MAIS), desenvolvido por Borges-Andrade (1982), o modelo CIPP (Contexto, Insumo, Processo e Produto) de Stufflebeam (1983), o modelo de Dutra (1984) e mais recentemente, o também modelo brasileiro IMPACT de autoria de Abbad-OC (1999).

Antes de perpassar por diversos modelos vale a pena a pergunta: Quais os níveis de análise da avaliação de treinamento e desenvolvimento de pessoas? Ou ainda quais os pontos passíveis de serem investigados? Nesse sentido, o modelo IMPACT de Abbad-OC (1999) exposto na Figura 1, por ter um caráter mais operacional e, sobretudo, por o modelo ter sido tentado com sucesso no transbordamento do contexto empresarial para o contexto acadêmico (SOUZA, 2002), mostrou-se plenamente adaptado e adequado aos objetivos da presente pesquisa, servindo de base teórica para o questionário aqui validado.

Figura 1: Modelo Integrado de Avaliação do Impacto do Treinamento no Trabalho IMPACT.

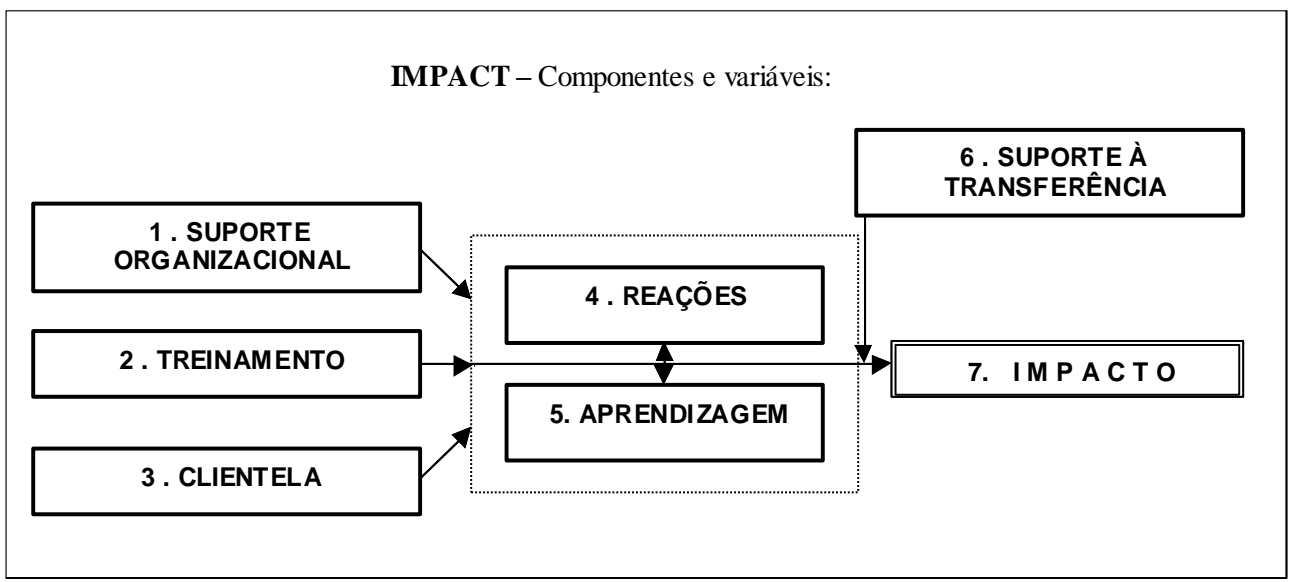

(Fonte: Abbad-OC, 1999.)

O conceito de Impacto para Abbad-OC (1999) compreende os conceitos de transferência de treinamento e desempenho. A transferência de treinamento é um constructo que pressupõe que o participante transfere para o ambiente de trabalho habilidades, conhecimentos e atitudes; enfim, no presente contexto, o significado é que o docente ultrapassa o contexto do estágio pós-doutoral e transfere para o trabalho uma nova forma de atuar.

Visando à construção de instrumento de medida capaz de mensurar a percepção por parte dos docentes acerca do impacto do pós-doutorado sobre as 
atividades de ensino e pesquisa, desenvolveu-se o questionário com base em pesquisa de campo e em revisão da literatura sobre o tema. A seguir, descreve-se a metodologia empregada na construção e validação deste questionário.

\section{MÉTODO DE DESENVOLVIMENTO E VALIDAÇÃO DO QUESTIONÁRIO}

O questionário de Percepção de impacto pós-doutoral nos processos de ensino e pesquisa foi desenvolvido e validado de acordo com as seguintes etapas: (1) adaptação da escala não psicométrica exposta na literatura em Souza (2002); (2) validação semântica; (3) validação teórica do conteúdo; e (4) validação empírica do conteúdo do questionário.

Inicialmente a coleta foi operacionalizada com base na própria cultura e estrutura universitária; isto é, conforme sugerido em Souza (2002), com três componentes que seriam passíveis de haver percepção de impacto: Pesquisa Ensino - Extensão (Figura 2).

Figura 2. Sistematização inicial e pré-operacionalização das variáveis do modelo de análise, para a construção do questionário de investigação.

\begin{tabular}{|c|c|l|}
\hline \multirow{2}{*}{$\begin{array}{c}\text { Percepção de Impacto } \\
\text { no Sistema de Pós- } \\
\text { Graduação }\end{array}$} & $\begin{array}{c}\text { Efeitos no } \\
\text { ensino }\end{array}$ & $\begin{array}{l}\text { Grau percebido em que o Pós- } \\
\text { doutorado produziu melhorias nas } \\
\text { atividades de ensino da pós-graduação }\end{array}$ \\
\cline { 2 - 3 } & $\begin{array}{c}\text { Efeitos na } \\
\text { pesquisa }\end{array}$ & $\begin{array}{l}\text { Grau percebido em que o Pós- } \\
\text { doutorado produziu melhorias nas } \\
\text { atividades de pesquisa. }\end{array}$ \\
\cline { 2 - 3 } & $\begin{array}{c}\text { Efeitos na na } \\
\text { extensão }\end{array}$ & $\begin{array}{l}\text { Grau percebido em que o Pós- } \\
\text { doutorado produziu melhorias nas } \\
\text { atividades de extensão. }\end{array}$ \\
\hline
\end{tabular}

O questionário perceptual elaborado para fins dessa pesquisa foi constituído basicamente de escalas e perguntas fechadas, que foram adaptados daqueles utilizados originalmente por Abbad-OC (1999) e depois adaptados por Souza (2002). O processo de adaptação em sua maioria foram modificações na redação dos itens, trocando-se termos de referência como treinamento por pósdoutorado; organização por IES, etc.:

Por exemplo: Item na escala original proposta por Abbad-OC (1999):

Aproveito as oportunidades que tenho para colocar em prática o que me foi ensinado no treinamento. Item adaptado compondo a escala de Souza (2002):

Aproveito todas as oportunidades que tenho para colocar em prática o que foi desenvolvido no curso.

Item adaptado para fins dessa pesquisa: Aproveito todas as oportunidades que tenho para colocar em prática o que foi desenvolvido no pós-doc.

Além da simples adaptação com a troca de termos de referência, também foram excluídos diversos itens dos instrumentos utilizados por Abbad-OC (1999) que não se aplicavam às atividades e a situação vivida pelos docentes em relação aos estágios de pós-doutorados. Exemplo: "Tenho sido encorajado pela minha chefia imediata a aplicar, no meu trabalho, o que aprendi no treinamento", na aferição do suporte à transferência. 
Foram acrescentados ainda, itens relativos ao impacto dos estágios de pósdoutorado no sistema de pós-graduação que não integram as escalas de investigação de Abbad-OC (1999), mas se encontram no instrumento de investigação de impacto dos cursos de mestrado e doutorado na Universidade utilizado por Souza (2002). Exemplo: "Quando os docentes concluem cursos de doutorado, geralmente proporcionam a seus alunos um conteúdo mais aprofundado do que antes, nas disciplinas que ministram"; item adaptado para o contexto da atual pesquisa: "Os alunos de pós-graduação têm acesso a um conteúdo mais aprofundado quando disciplinas são ministradas por docentes que realizaram o pós-doutorado".

Uma vez construídos os itens do instrumento de coleta de dados, verificou-se que os mesmos, de forma geral, satisfaziam do ponto de vista das técnicas psicométricas de construção de itens integrantes de escalas (PASQUALI, 1996, 1997). Notadamente, dentre os critérios relevantes listados pelo autor, garantiuse que os mesmos atingiam em especial o critério da clareza e o critério da simplicidade.

O Critério da clareza diz respeito ao item ser inteligível e compreensível para todos os estratos da população alvo. A simplicidade é relacionada com a expressão de uma ideia única. Itens que introduzam explicações de termos podem tornar-se confusos, aumentando a magnitude do erro de aferição de uma escala. Apesar do pesquisador poder interferir previamente neste processo ao formular/alterar formas da frase, etc., vale aqui frisar que boa parte desses critérios são alcançados por intermédio da análise semântica.

$\mathrm{Na}$ direção de um aumento de qualidade os itens construídos acerca da percepção de impacto pós-doutoral passaram pelo processo denominado de análise semântica, que conforme pontuam Castro e Borges-Andrade (2004) possui os seguintes objetivos:

a) verificar a compreensão dos itens pelo público alvo;

b) observar se há ambiguidade nos itens ou se os mesmos apresentam uma única ideia com palavras claras e de fácil compreensão;

c) modificar itens quando necessário ampliar a clareza; reformular, substituir ou eliminar itens quando verificada a existência de termos ambíguos, e;

d) verificar a representatividade dos itens propostos.

Em que pese assim a sua relevância, a validação semântica ocorreu com análise de juízes, que consensualmente julgaram como itens inteligíveis para o público-alvo. Provavelmente, isso se deve ao fato de que boa parte dos itens construídos foram advindos dos itens que constituíram o instrumento de investigação utilizado por Souza (2002), para a investigação do impacto da qualificação docente nos resultados de uma universidade e, portanto, os itens parecem que já estavam (pré)adaptados qualitativamente em sua linguagem e conteúdo ao público alvo desta pesquisa que era também o mesmo no estudo citado [docentes universitários].

A partir dessas análises foi possível identificar e selecionar os itens iniciais para compor a primeira versão do questionário preliminar de Percepção de Impacto 
três instâncias ou três fatores a serem investigados (Figura 2). As três escalas foram submetidas na quarta etapa a procedimentos de validação empírica.

Nessa última etapa, o questionário com itens associados a uma escala Likert de concordância, foi aplicado em uma amostra de 978 docentes, de todo o território nacional egressos do programa de pós-doutoramento no exterior promovido pela Coordenação de Aperfeiçoamento de Pessoal de Nível Superior (CAPES). As respostas dessa amostra foram submetidas a análises descritivas e fatoriais com rotação oblíqua e cálculos de confiabilidade (Alfa de Cronbach). Os resultados desse trabalho estão descritos a seguir.

\section{RESULTADOS E DISCUSSÃO}

A Tabela 1 expõe a área do conhecimento de atuação dos 978 docentes participantes da validação empírica do questionário proposto e mostra de uma forma contundente que os itens são adequados aos docentes universitários aplicando-se de forma satisfatória à diversidade acadêmica e as diversas áreas do conhecimento, não mostrando deficiências ou limitações nesse sentido.

No que tange à área de atuação dos docentes participantes, a amostra de 978 professores cobriu 73 áreas do conhecimento (somada mais o campo multidisciplinar), somente as áreas de arqueologia, engenharia nuclear, engenharia de pesca, contábeis e turismo, pertencentes respectivamente às grandes áreas de Humanas, Engenharias, Agrárias e as duas últimas à Sociais Aplicadas, não foram representadas pela devolutiva dos questionários para composição do estudo.

Convém frisar, a título de esclarecimento, que os dados de atuação da Tabela 1 , não derivam das informações constantes do currículo Lattes, mas sim da resposta ou do como docente se identificou ao responder o instrumento de pesquisa. Essa estratégia foi adotada para possibilitar entre outras coisas, um dado de pesquisa mais afinado com a atuação docente cotidiana e não exclusivamente com a formação formal constante do Lattes e também para possibilitar o aparecimento da área multidisciplinar (não constante do sistema).

Tabela 1 - Distribuição dos pesquisadores com pós-doutorado na amostra e suas respectivas áreas.

\begin{tabular}{lcclcc}
\multicolumn{1}{c}{ Área } & Número & Percentual & \multicolumn{1}{c}{ Área } & Número & Percentual \\
\hline Biologia Geral & 2 & $0,2 \%$ & $\begin{array}{l}\text { Eng. } \\
\text { Aeroespacial }\end{array}$ & 4 & $0,41 \%$ \\
Biofísica & 2 & $0,2 \%$ & $\begin{array}{l}\text { Eng. } \\
\text { Biomédica }\end{array}$ & 6 & $0,61 \%$ \\
Bioquímica & 13 & $1,33 \%$ & $\begin{array}{l}\text { Eng. de } \\
\text { Materiais }\end{array}$ & 7 & $0,72 \%$ \\
Botânica & 3 & $0,31 \%$ & $\begin{array}{l}\text { Engenharia } \\
\text { Civil }\end{array}$ & 18 & $1,84 \%$ \\
Ecologia & 10 & $1,02 \%$ & $\begin{array}{l}\text { Engenharia } \\
\text { de Minas }\end{array}$ & 1 & $0,1 \%$ \\
Farmacologia & 7 & $0,72 \%$ & $\begin{array}{l}\text { Eng. de } \\
\text { Produção }\end{array}$ & 6 & $0,61 \%$
\end{tabular}




\begin{tabular}{|c|c|c|c|c|c|}
\hline Fisiologia & 17 & $1,74 \%$ & $\begin{array}{l}\text { Engenharia } \\
\text { de }\end{array}$ & & \\
\hline Genética & 11 & $1,12 \%$ & Transportes & 3 & $0,31 \%$ \\
\hline Imunologia & 7 & $0,72 \%$ & $\begin{array}{l}\text { Engenharia } \\
\text { Elétrica }\end{array}$ & 24 & $2,45 \%$ \\
\hline Microbiologia & 11 & $1,12 \%$ & $\begin{array}{l}\text { Engenharia } \\
\text { Mecânica }\end{array}$ & 23 & $2,35 \%$ \\
\hline Morfologia & 5 & $0,51 \%$ & $\begin{array}{l}\text { Engenharia } \\
\text { Oceânica }\end{array}$ & 1 & $0,1 \%$ \\
\hline Parasitologia & 5 & $0,51 \%$ & $\begin{array}{l}\text { Engenharia } \\
\text { Química }\end{array}$ & 10 & $1,02 \%$ \\
\hline Zoologia & 8 & $0,82 \%$ & $\begin{array}{l}\text { Engenharia } \\
\text { Sanitária }\end{array}$ & 9 & $0,92 \%$ \\
\hline Biológicas & 101 & $10,3 \%$ & Engenharias & 112 & $11,5 \%$ \\
\hline Administração & 22 & $2,25 \%$ & & & \\
\hline $\begin{array}{l}\text { Arquitetura e } \\
\text { Urbanismo }\end{array}$ & 13 & $1,33 \%$ & $\begin{array}{l}\text { Educação } \\
\text { Física }\end{array}$ & 10 & $1,02 \%$ \\
\hline $\begin{array}{l}\text { Ciência da } \\
\text { Informação }\end{array}$ & 4 & $0,41 \%$ & $\begin{array}{l}\text { Enfermage } \\
\mathrm{m}\end{array}$ & 13 & $1,33 \%$ \\
\hline Comunicação & 19 & $1,94 \%$ & Farmácia & 12 & $1,23 \%$ \\
\hline Demografia & 4 & $0,41 \%$ & Fisioterapia & 2 & $0,2 \%$ \\
\hline $\begin{array}{l}\text { Desenho } \\
\text { Industrial }\end{array}$ & 3 & $0,31 \%$ & $\begin{array}{l}\text { Fonoaudiol } \\
\text { ogia }\end{array}$ & 2 & $0,2 \%$ \\
\hline Direito & 18 & $1,84 \%$ & Medicina & 50 & $5,11 \%$ \\
\hline Economia & 20 & $2,04 \%$ & Nutrição & 3 & $0,31 \%$ \\
\hline Museologia & 1 & $0,1 \%$ & $\begin{array}{l}\text { Odontologi } \\
\text { a } \\
\text { Terapia }\end{array}$ & 22 & $2,25 \%$ \\
\hline Serviço Social & 6 & $0,61 \%$ & Ocupaciona & 2 & $0,2 \%$ \\
\hline $\begin{array}{l}\text { Planejamento } \\
\text { Urbano }\end{array}$ & 6 & $0,61 \%$ & $\begin{array}{l}\text { Saúde } \\
\text { Coletiva }\end{array}$ & 19 & $1,94 \%$ \\
\hline $\begin{array}{c}\text { Sociais } \\
\text { Aplicadas }\end{array}$ & 116 & $11,9 \%$ & Saúde & 135 & $13,8 \%$ \\
\hline Antropologia & 20 & $2,04 \%$ & & & \\
\hline Ciência Política & 7 & $0,72 \%$ & Astronomia & 6 & $0,61 \%$ \\
\hline Educação & 41 & $4,19 \%$ & $\begin{array}{l}\text { Computaçã } \\
\text { o }\end{array}$ & 29 & $2,97 \%$ \\
\hline Filosofia & 32 & $3,27 \%$ & Estatística & 3 & $0,31 \%$ \\
\hline Geografia & 10 & $1,02 \%$ & Física & 33 & $3,37 \%$ \\
\hline História & 35 & $3,58 \%$ & Química & 37 & $3,78 \%$ \\
\hline Psicologia & 24 & $2,45 \%$ & Geociências & 21 & $2,15 \%$ \\
\hline Sociologia & 29 & $2,97 \%$ & $\begin{array}{l}\text { Matemátic } \\
\text { a }\end{array}$ & 26 & $2,66 \%$ \\
\hline Teologia & 1 & $0,1 \%$ & $\begin{array}{l}\text { Oceanograf } \\
\text { ia }\end{array}$ & 5 & $0,51 \%$ \\
\hline Humanas & 199 & $20,3 \%$ & $\begin{array}{c}\text { Exatas e da } \\
\text { Terra }\end{array}$ & 160 & $16,4 \%$ \\
\hline Agronomia & 28 & $2,86 \%$ & Artes & 14 & $1,43 \%$ \\
\hline
\end{tabular}




\begin{tabular}{|c|c|c|c|c|c|}
\hline $\begin{array}{l}\text { Engenharia } \\
\text { Agrícola }\end{array}$ & 2 & $0,2 \%$ & Letras & 35 & $3,58 \%$ \\
\hline $\begin{array}{l}\text { Engenharia } \\
\text { Florestal }\end{array}$ & 5 & $0,51 \%$ & Linguística & 17 & $1,74 \%$ \\
\hline $\begin{array}{l}\text { Medicina } \\
\text { Veterinária }\end{array}$ & 8 & $0,82 \%$ & $\begin{array}{c}\text { Letras, } \\
\text { Linguística e }\end{array}$ & & \\
\hline $\begin{array}{l}\text { Tecnologia de } \\
\text { Alimentos }\end{array}$ & 7 & $0,72 \%$ & Artes & 66 & $6,7 \%$ \\
\hline Zootecnia & 15 & $1,53 \%$ & & & \\
\hline \multirow[t]{2}{*}{ Agrárias } & 65 & $6,6 \%$ & $\begin{array}{l}\text { Multidiscipli } \\
\text { nar }\end{array}$ & 24 & $2,5 \%$ \\
\hline & & & Total & 978 & $100,0 \%$ \\
\hline
\end{tabular}

Diante da amostra expressiva de docentes, os itens perceptuais de impacto, foram testados em conjunto em uma matriz de correlação extraída por meio da Kayse-Meyer-Olkin measure of sampling adequacy (KMO) sendo encontrado um alto valor de fatorabilidade (KMO =0,903). Em uma análise semântica e teórica (Figura 2), observava-se que a matriz até poderia ser pensada em três fatores, mas vamos os fatos empíricos de validação.

A escala perceptual de impacto na pós-graduação possuiu um KMO com valor de 0,903 , o que é considerado excelente e indicando que todos os itens de percepção de impacto na pós-graduação são certamente fatoráveis (inicialmente pensado conforme o Figura 2, em três fatores, mas nesse caso, também testado em outras possibilidades). Trazendo a nova perspectiva inserida na atual pesquisa, como válida, que era o de mensurar não a percepção de impacto sobre o desempenho individual (conforme expresso tradicionalmente na literatura da área de TD\&E), mas sim também propriamente a mensuração das crenças, das opiniões e da percepção de impacto do pós-doutorado sobre o coletivo, nesse caso, sobre o sistema de pós-graduação.

Diante do "sinal verde" fornecido pelo índice do KMO, seguiu-se à avaliação dos itens construídos com o método de fatoração por meio da análise dos componentes principais (Principal Component Analysis), com os componentes das matrizes rotacionadas obliquamente (método Direct Oblimin). Como resultado obteve-se uma saída que indicava dois fatores (Tabela 2 - porção esquerda). A interpretação dos fatores, então, foi feita por meio de análise de conteúdo semântico dos itens que compunham cada fator, tendo sido dada especial atenção aos que apresentaram maiores cargas.

Com base em uma interpretação de conteúdo semântico, a matriz default que é construída tendo por referência os autovalores (eigenvalue) e em uma perspectiva trazida automaticamente pelo software de análise, essa matriz trouxe claramente dois fatores, sendo que o fator 01 agrupava os itens referentes à percepção de impacto na pesquisa e o fator 02 unia os itens com assertivas relativas à percepção de impacto na extensão universitária.

Há que se observar que há uma espécie de meio termo que se traduz na Tabela 2 justamente nos dois itens (Q_53 e Q_54) que são referentes à avaliação de percepção de impacto sobre o ensino. Pelos autovalores, a situação posta é como se o ensino fosse empiricamente uma dimensão híbrida ou um elo de ligação entre a extensão e a pesquisa. 
Na porção mais à esquerda da Tabela 2 observa-se o ensino integrado à pesquisa (isto é, pertencendo também ao segundo fator) e também o ensino integrado à extensão, possuindo cargas fatoriais que o habilitavam também a pertencer a esse primeiro componente ou fator. Neste cenário bifatorial o que estaria desenhado seriam duas variáveis critérios: a variável ensino e extensão e a variável ensino e pesquisa. Nesse desenho de dois fatores com o ensino assumindo uma posição híbrida, o modelo fatorial é capaz de explicar $66 \%$ da variância das respostas dos participantes.

Tabela 2 - Estrutura da matriz fatorial construída com base nos autovalores e também da matriz forçada a três fatores, para os itens de percepção de impacto na pós-graduação.

Estrutura da Matriz baseada nos autovalores

\begin{tabular}{|c|c|c|c|c|c|c|}
\hline \multirow[b]{2}{*}{ Itens } & \multirow[b]{2}{*}{ Conteúdo dos itens } & \multicolumn{2}{|c|}{ Componentes } & \multicolumn{3}{|c|}{ Componentes } \\
\hline & & $\begin{array}{c}\text { Fator } \\
01 \\
\end{array}$ & $\begin{array}{c}\text { Fator } \\
02 \\
\end{array}$ & $\begin{array}{c}\text { Fator } \\
01 \\
\end{array}$ & $\begin{array}{c}\text { Fator } \\
02 \\
\end{array}$ & $\begin{array}{c}\text { Fator } \\
03\end{array}$ \\
\hline Q_51 & $\begin{array}{l}\text { Os estágios de pós-doc realizados } \\
\text { por docentes fornecem suporte à } \\
\text { busca de financiamento para as } \\
\text { atividades de extensão realizadas } \\
\text { em IES }\end{array}$ & 0,422 & 0,885 & 0,417 & 0,935 & $\begin{array}{l}- \\
0,44 \\
2\end{array}$ \\
\hline Q_52 & $\begin{array}{l}\text { A realização do pós-doutorado } \\
\text { costuma facilitar a realização de } \\
\text { um maior número de projetos de } \\
\text { extensão em IES }\end{array}$ & 0,418 & 0,898 & 0,401 & 0,931 & $\begin{array}{l}- \\
0,48 \\
1\end{array}$ \\
\hline Q_53 & $\begin{array}{l}\text { Os alunos de pós-graduação têm } \\
\text { acesso a um conteúdo mais } \\
\text { aprofundado quando disciplinas } \\
\text { são ministradas por docentes que } \\
\text { realizaram o pós-doc }\end{array}$ & 0,572 & 0,688 & 0,434 & 0,448 & $\begin{array}{l}- \\
0,87 \\
6\end{array}$ \\
\hline Q_54 & $\begin{array}{l}\text { Após concluírem estágios pós- } \\
\text { doutorais os docentes costumam } \\
\text { realizar mais atividades de ensino } \\
\text { na pós-graduação stricto sensu nas } \\
\text { IES }\end{array}$ & 0,556 & 0,692 & 0,444 & 0,616 & $\begin{array}{l}- \\
0,81 \\
4\end{array}$ \\
\hline Q_55 & $\begin{array}{l}\text { A realização do pós-doutorado } \\
\text { contribui para que os docentes } \\
\text { aumentem o número de pesquisas } \\
\text { que realizam em IES }\end{array}$ & 0,798 & 0,494 & 0,735 & 0,433 & $\begin{array}{l}- \\
0,70 \\
9\end{array}$ \\
\hline Q_56 & $\begin{array}{l}\text { A realização do pós-doc pelos } \\
\text { docentes melhora a qualidade das } \\
\text { pesquisas que realizam em IES }\end{array}$ & 0,862 & 0,492 & 0,798 & 0,302 & $\begin{array}{l}- \\
0,71 \\
3\end{array}$ \\
\hline Q_57 & $\begin{array}{l}\text { A realização do pós-doutorado } \\
\text { pelos docentes contribui para a } \\
\text { busca de financiamento das } \\
\text { atividades de pesquisa }\end{array}$ & 0,770 & 0,404 & 0,783 & 0,351 & $\begin{array}{l}- \\
0,40 \\
7\end{array}$ \\
\hline
\end{tabular}

Estrutura da Matriz

forçada a três

fatores

tor 


\begin{tabular}{|c|c|c|c|c|c|c|}
\hline Q_58 & $\begin{array}{l}\text { A realização do estágio pós- } \\
\text { doutoral pelos docentes tem se } \\
\text { refletido em suporte para a } \\
\text { consolidação de grupos de } \\
\text { pesquisa em IES }\end{array}$ & 0,777 & 0,532 & 0,788 & 0,496 & $\begin{array}{l}- \\
0,44 \\
8\end{array}$ \\
\hline Q_59 & $\begin{array}{l}\text { A realização do pós-doutorado } \\
\text { pelos docentes melhora a } \\
\text { qualidade da produção intelectual } \\
\text { da pós-graduação em IES }\end{array}$ & 0,864 & 0,473 & 0,829 & 0,329 & $\begin{array}{l}- \\
0,61 \\
9\end{array}$ \\
\hline Q_60 & $\begin{array}{l}\text { A realização do pós-doutorado } \\
\text { pelos docentes facilita a construção } \\
\text { de redes de pesquisa ou } \\
\text { intercâmbios entre IES }\end{array}$ & 0,752 & 0,456 & 0,767 & 0,419 & $\begin{array}{l}- \\
0,40 \\
5\end{array}$ \\
\hline Q_61 & $\begin{array}{l}\text { A realização do pós-doutorado pelo } \\
\text { docente favorece a um maior } \\
\text { número de publicações em revistas } \\
\text { internacionais indexadas }\end{array}$ & 0,698 & 0,207 & 0,743 & 0,196 & $\begin{array}{l}- \\
0,21 \\
6\end{array}$ \\
\hline
\end{tabular}

Nota. IES = Instituições de Ensino Superior Método de Extração: Principal Component Analysis. Método de Rotação: Oblimin with Kaiser Normalization.

O cenário fatorial exposto na porção direita da Tabela 2 coloca a análise fatorial exploratória em uma tentativa de rotação forçada a três fatores (Teoricamente, a priori: Ensino-Pesquisa-Extensão), verificando como se comportou os itens relativos ao ensino nesse outro contexto, chama a atenção nesse caso que todas as cargas fatoriais do terceiro fator construído passaram a ser negativas, mas essas cargas podem ser analisadas em módulo (desconsiderando-se o sinal), somente para esclarecer a rotação varimax, também bastante utilizada em pesquisa, apresenta um resultado semelhante ao apontado e com todas as cargas positivas. E, considerando-se as cargas em módulo, o ensino continuou não sendo um fator particularizado, não se conseguia dissociá-lo da pesquisa ou da extensão, todas as cargas continuaram sendo superiores a 0,40 para todas as colunas apesar de mostrarem-se mais fortes para a coluna deste novo fator criado.

A correlação da percepção sobre o ensino é forte o suficiente para esta compor tanto a dimensão extensão quanto a dimensão pesquisa, nota-se que entre a pesquisa e a extensão esse distanciamento torna-se mais claro, mais fica muito mais difuso ao considerar a percepção de impacto sobre o ensino, que empiricamente assumiu um papel enquanto uma instância intermediária, que não possui limites definidos.

Em outras palavras o ensino assumiu um caráter permeador ou mediador entre a extensão e a pesquisa, permeando essas duas dimensões e se confundindo com elas, ou melhor, em prol da maior clareza, a percepção de impacto no ensino, está tão fortemente correlacionado com os dois outros fatores, que pode-se afirmar que ela faz parte e integra também essas duas instâncias: Extensão e Pesquisa.

A questão é: Se a dimensão ensino é sem fronteiras claramente definidas, que fronteiras meramente operacionais poderiam ser estabelecidas para fins de pesquisa? O que seria mais condizente: A estrutura da matriz padrão? Ou a 
estrutura da matriz desenhada com três fatores? Convém reforçar que, qualquer escolha, poderia ser considerada válida e fidedigna, pelos critérios estatísticos e psicométricos utilizados em pesquisa, todas possuem boas ou ótimas cargas fatoriais e apresentam bons índices de precisão.

No primeiro cenário teríamos duas variáveis critério uma de percepção sobre a extensão-ensino (itens 51, 52, 53 e 54) e outra de percepção de impacto sobre o ensino-pesquisa (itens $53,54,55,56,57,58,59$ e 61). No segundo cenário teríamos aparentemente fronteiras mais bem definidas, haveria três variáveis critério uma de percepção sobre a extensão universitária (itens 51 e 52), outra de percepção sobre a pesquisa (itens 55 a 61), ambas, como originalmente pensadas e a terceira que trataria da percepção sobre o planejamento e processos de ensino-pesquisa (itens 53, 54, 55 e 56), nesse segundo modelo fatorial a estrutura desenhada é capaz de explicar $72 \%$ da variância das respostas dos participantes.

Como se observa pelos conceitos culturais de ensino, pesquisa e extensão teoricamente todas as duas estruturas semanticamente fazem sentido e psicometricamente também ambas podem ser consideradas pela análise fatorial exploratória, potencialmente válidas e fidedignas.

Figura 3. Variância explicada pelos modelos e precisão das escalas para cada uma das matrizes estruturadas acerca da percepção de impacto nas atividades da pós-graduação.

\begin{tabular}{|l|l|}
\hline \multicolumn{2}{|c|}{ Estrutura da Matriz baseada nos autovalores } \\
\hline $\begin{array}{l}\text { Variância explicada pelo } \\
\text { modelo }\end{array}$ & $66 \%$ \\
\hline \multirow{2}{*}{ Alphas de Cronbrach } & Fator 01 (extensão-ensino) $\alpha=0,848$ \\
\cline { 2 - 2 } & Fator 02 (ensino-pesquisa) $\alpha=0,90$ \\
\hline \multicolumn{2}{|c|}{ Estrutura da Matriz forçada a três fatores } \\
\hline $\begin{array}{l}\text { Variância explicada pelo } \\
\text { modelo }\end{array}$ & $72 \%$ \\
\hline \multirow{3}{*}{ Alphas de Cronbrach } & Fator 01 (extensão) $\alpha=0,891$ \\
\cline { 2 - 2 } & Fator 02 (pesquisa) $\alpha=0,898$ \\
\cline { 2 - 2 } & $\begin{array}{l}\text { Fator 03 (planejamento e processos de ensino- } \\
\text { pesquisa) } \quad \alpha=0,836\end{array}$ \\
\hline
\end{tabular}

No entanto, se do ponto de vista psicométrico ambas fazem sentido; do ponto de vista da práxis acadêmica brasileira na pós-graduação, a segunda estrutura fatorial parece estar mais condizente, pois os itens de impacto no ensino não estariam dissociados da extensão, mas estariam mais próximos dos itens relativos não a produtos de pesquisa, mas aos processos e/ou a execução dos projetos de pesquisa.

Observando-se a Figura 3 enxerga-se que, de uma forma geral, o caráter de empate também prevalece ao buscar-se o poder de explicação dos modelos e a precisão das escalas medida pelo Alpha de Cronbrach. No entanto urge uma saída que se estabeleça, que não seja meramente, casual ou de um "uni-duni-tê" e até mesmo arbitrada seja pelo pesquisador, seja pelo software baseado no default dos autovalores maiores do que 1.

O poder de explicação da variância é um pouco maior na segundo estrutura composta por três fatores (66\% versus $72 \%$ ), somado a isso, a escala de percepção de impacto em pesquisa perde muito pouco a sua confiabilidade quando analisada 
de uma forma específica e não condensada com a percepção de impacto em ensino - há uma diferença de apenas dois milésimos no que diz respeito ao alpha $(0,900$ versus 0,898 ).

Desta forma tendo em vista que a segunda estrutura apresentou scores muito próximos ao da primeira estrutura fatorial, mas possuiu um poder de explicação da variância maior, possuiu ótimos índices de precisão, agrupou itens teoricamente coerentes aos conceitos de ensino-pesquisa-extensão, possuiu um conteúdo que faz sentido semântico e em especial também desenhou um framework mais claro ao levar-se em conta a prática acadêmica brasileira em que o ensino na pós-graduação encontra-se mais vinculado aos processos de pesquisa do que à extensão; dessa forma, diante dessas justificativas a opção operacional foi pela estrutura fatorial que considerou três fatores.

Surge assim a escala de Percepção de impacto pós-doutoral em processos de ensino-pesquisa, adicional, de característica mesclada e à parte das demais escalas. O que não foi pensada inicialmente do ponto de vista teórico, mas mostrou-se no mundo empírico como uma corroboração do discurso, de que várias atividades universitárias de fato são indissociáveis. Essa escala construída e validada ficou composta por quatro itens de investigação de impacto e pode ser considerada confiável, uma vez que obteve alto índice de consistência $(\alpha=0,836)$, conforme detalhamento na Tabela 3.

Tabela 3 - Cargas fatoriais e comunalidades (h2) para os itens dos fatores de percepção de impacto pós-doutoral em processos de ensino-pesquisa.

\begin{tabular}{|c|c|c|c|c|}
\hline $\begin{array}{l}\text { Código } \\
\text { do item }\end{array}$ & Assertiva de investigação & $\begin{array}{l}\text { Carga } \\
\text { Fatorial }\end{array}$ & $h^{2}$ & $\begin{array}{l}\alpha \text { sem } \\
\text { o item }\end{array}$ \\
\hline Q_53 & $\begin{array}{l}\text { Os alunos de pós-graduação têm acesso a } \\
\text { um conteúdo mais aprofundado quando } \\
\text { disciplinas são ministradas por docentes } \\
\text { que realizaram o pós-doutorado. }\end{array}$ & $-0,88$ & 0,773 & 0,776 \\
\hline Q_54 & $\begin{array}{l}\text { Após concluírem estágios pós-doutorais os } \\
\text { docentes costumam realizar mais } \\
\text { atividades de ensino na pós-graduação } \\
\text { stricto sensu nas IES. }\end{array}$ & $-0,81$ & 0,748 & 0,802 \\
\hline Q_55 & $\begin{array}{l}\text { A realização do pós-doc contribui para que } \\
\text { os docentes aumentem o número de } \\
\text { pesquisas que realizam em IES. }\end{array}$ & $-0,71$ & 0,707 & 0,795 \\
\hline Q_56 & $\begin{array}{l}\text { A realização do pós-doc pelos docentes } \\
\text { melhora a qualidade das pesquisas que } \\
\text { realizam em IES. }\end{array}$ & $-0,72$ & 0,793 & 0,796 \\
\hline & $\begin{array}{r}\text { Fator: Percepção de impacto em processos } \\
\text { de ensino-pesquisa. }\end{array}$ & $\begin{array}{r}\mathbf{N}^{\circ} \text { de } \\
\text { itens }=4\end{array}$ & & $\begin{array}{r}\alpha= \\
0,836\end{array}$ \\
\hline
\end{tabular}

No questionário aqui denominado de Percepção de Impacto em Processos de Ensino-Pesquisa, como observa-se na Tabela 3, encontram-se itens mais direcionados para as atividades de ensino na pós-graduação e para os processos da pesquisa, e não para os seus produtos, como a exemplo dos itens Q_55 e Q_56 que são aparentemente mais voltados para o intra-desenvolvimento da pesquisa do que para os seus outputs (a exemplo das publicações). 
O questionário de Percepção de Impacto em Processos de Ensino-Pesquisa, além de facilitar a produção de conhecimentos científicos futuros na área de comportamento organizacional, especialmente no campo do Treinamento, Desenvolvimento e de Educação Corporativa, pode sair do campo acadêmico de investigação e ser plenamente aplicável à área de Gestão de Ciência e Tecnologia e à área de Administração Educacional, como instrumento de avaliação e de feedback, e poderá vir a ser útil como instrumento de diagnóstico e também como indicador indireto de necessidades estratégicas de investimento/treinamento gerencial nas áreas de gestão de conhecimento e práticas de valorização do docente, a fim de investigar de que modo as percepções do trabalhador pesquisador estão relacionadas com os níveis mais subjetivos do impacto da capacitação realizada por meio dos estágios pós-doutorais. 


\title{
Impact post-doctoral perceived at processes of teaching-research: development and validation of a questionnaire.
}

\begin{abstract}
The faculty training specialized literature has been considering the importance the research post-doctoral, but in accordance with framework exposed in Castro and Porto (2016), is focused in production at journals, only, not considering the perception of professors. Part of this is due to lack of reliable instruments to the investigation in amplitude of the perceptions, especially at the graduate system teaching-research processes. This work reports the experience in developing of questionnaire in this sense. The items constructed were tested with 978 professors and their responses were submitted to a factorial analysis with oblique rotation, and produced two types of empirical structures, based in the structures, emerged the scale of perception de post-doctoral impact at teaching-research process with a high reliability score. With the, proper validation, are discussed the applications of this questionnaire in research on evaluation of continuing education programs, and suggested further studies and applications in this sense evaluative.
\end{abstract}

KEYWORDS: Psychometry. Training, development and education. Professional capacity. Measurement in evaluation. Management of science and technology. Continuing education. 


\section{REFERÊNCIAS}

ABBAD-OC, G. Um modelo integrado de avaliação do impacto do treinamento: IMPACT. 1999. 262f, Tese (Doutorado em Psicologia), Instituto de Psicologia, Universidade de Brasília, Brasília. 1999.

BASTOS, A. V. B. O suporte oferecido pela pesquisa na área de treinamento. Revista de Administração - RAUSP. São Paulo, v. 26, n. 4, p. 87-102, 1991.

BOOG, G. Desenvolvimento de recursos humanos: investimento com retorno? São Paulo: McGraw-Hill. 1980. 125 p.

BORGES-ANDRADE, J. E. Avaliação somativa de sistemas instrucionais: integração de três propostas. Tecnologia Educacional, Rio de Janeiro, v. 11, n. 46, p. 29-39, 1982.

BORGES-ANDRADE, J. E. Desenvolvimento de medidas em avaliação de treinamento. Estudos de Psicologia, Natal, v. 7, (número especial), p. 31-43. 2002. Doi: http://dx.doi.org/10.1590/S1413-294X2002000300005

BORGES-ANDRADE, J. E.; ABBAD, G. S.; MOURÃO, L. Treinamento, Desenvolvimento e Educação em Organizações e Trabalho: fundamentos para a gestão de pessoas. Porto Alegre: Artmed/Bookman. 2006. 576 p.

CASTRO, P. M. R.; BORGES-ANDRADE, J. E. Identificação das Necessidades de Capacitação Profissional. Revista de Administração - RAUSP, São Paulo, v. 39, n. 1, p. 96-108, 2004.

CASTRO, P. M. R.; PORTO, G. S. Copo meio cheio ou copo meio vazio? Estágio pós-doutoral, face exposta, revisão crítica e agenda de pesquisa. Educação em Revista. Belo Horizonte, v. 32, n. 1, p. 159-184, 2016. Doi:

http://dx.doi.org/10.1590/0102-4698140410

DRUCKER, P. Sociedade pós-capitalista. São Paulo: Pioneira. 1993. 186 p.

DUTRA, M. L. Avaliação de Treinamento. Tecnologia Educacional, Rio de Janeiro, v. 13, n. 57, p. 14-26, 1984.

HAMBLIN, A. Avaliação e controle do treinamento. São Paulo: McGraw-Hill do Brasil. 1978. 
LORENZ, K. M. Índices de avaliação para programas de treinamento de recursos humanos. Tecnologia Educacional, Rio de Janeiro, v. 9, n. 37, p. 15-21, 1980.

MOURÃO, L.; PUENTE-PALACIOS, K. E. Formação Profissional. In: Treinamento, Desenvolvimento e Educação em Organizações e Trabalho. BORGES-ANDRADE, J.E.; ABBAD, G.S.; MOURÃO, L. (Orgs), pp. 41-64, Porto Alegre: Artmed/Bookman. 2006.

NONAKA, I.; TAKEUCHI, H. Criação de conhecimentos na empresa: como as empresas japonesas geram a dinâmica da inovação. Rio de Janeiro: Campus. 1997. $358 \mathrm{p}$.

PASQUALI, L. Medidas Escalares. Teoria e métodos de medida em ciências do comportamento, cap 4. Brasília: MEC/INEP. 1996.

PASQUALI, L. Instrumentalização no Estudo das Organizações: A utilização de Escalas Psicométricas. In: Trabalho, Organizações e Cultura. TAMAYO, A.; BORGES-ANDRADE, J. E.; CODO, W (Orgs). pp. 75-82. São Paulo, Cooperativa de Autores Associados, 1997.

SCHNEIDER, B. Is the sky really falling? A view of the future. In: Evolving Practices in Human Resource Management. KRAUT, I.; KORMAN, A. K. (Orgs). pp. 328-357. San Francisco, Jossey-Bass, 1999.

SCHULTZ, T. O capital humano: investimento em educação e pesquisa. Rio de Janeiro: Zarhar Editores, 1973. 250 p.

SENGE, P. A quinta disciplina: arte e prática da organização que aprende. 5 ed. São Paulo: Best Seller. 1999. 441 p.

SOUZA, V. C. Impacto da qualificação docente nos resultados de uma universidade: o caso da UFBA. 2002. 153f. Dissertação (Mestrado em Administração), Faculdade de Estudos Sociais Aplicados, Universidade de Brasília, Brasília. 2002. models: viewpoints on educational and human services evaluation. MADAUS, G.F.; KELLAGHAN, T.; STUFFLEBEAM, D. L. (Eds.), pp. 279-318. Boston: Mass Kluwer, 1983. 
Recebido: 2016-08-05

Aprovado: 2019-04-26

DOI: $10.3895 /$ rbect.v12n2.4501

Como citar: CASTRO, P. M. R.; PORTO, G. S. Percepção de impacto pós-doutoral nos processos de ensino-pesquisa: desenvolvimento e validação de um questionário. Revista Brasileira de Ensino de Ciência e Tecnologia, v. 12, n. 2, 2019. Disponível em: <https://periodicos.utfpr.edu.br/rbect/article/view/4501>. Acesso em: xxx.

Correspondência: Pedro Marcos Roma de Castro - pedro.castro@capes.gov.br Direito autoral: Este artigo está licenciado sob os termos da Licença Creative Commons-Atribuição 4.0 Internacional. 